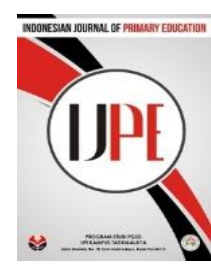

Vol. 3, No. 1 (2019) 93-100 ISSN: 2597-4866

Indonesian Journal of Primary Education

IJPH

\title{
Pengaruh Media Cerita Bergambar terhadap Membaca Pemahaman pada Teks Dongeng
}

\author{
Neng Wuan Marisa ${ }^{1}$, Hodidjah $^{2}$, Oyon Haki Pranata ${ }^{3}$ \\ Universitas Pendidikan Indonesia Kampus Tasikmalaya \\ *Corresponding author: wulan11marisa@gmail.com ${ }^{1}$, hodidjah2017@gmail.com², oyonhakipranata@upi.edu ${ }^{3}$
}

Diterima 25 April; 2019; Direview 15 Mei 2019; Diterima 29 Mei 2019

Diterbitkan online 25 Juni 2019

\begin{abstract}
This research is based on the students interesting and enthusiastic to reading story is low, the problem is students doesn't understand the story that their read. To solved this problem, the researcher chooses a pictorial story concrete media to improve reading comprehension of students on learning Indonesian. The formulation of the problem in this research generally how influence pictorial story media to reading comprehension on narrative texts in $3^{\text {rd }}$ grader SD Negeri Mancogeh Cipedes Subdistrict Tasikmalaya City. The purpose of this research general is to know the influence pictorial story media to reading comprehension on narrative texts in $3^{\text {rd }}$ grader SD Negeri Mancogeh Cipedes Subdistrict Tasikmalaya City. The method in this research is used Quasi Experimental with Nonequivalent Control Group Design type. Technique of collecting data in this research is test, observation and documentation. The population in this research is the $3^{\text {rd }}$ grade SD Negeri Mancogeh, the technique in the form of saturated sampling. As for the instrument used are a matter of the form of description questions test. Quantitative data analysis use Software Microsoft Excel 2010 and program SPSS version 16.0. After the research was performed, the data obtained are then processed and analyzed, so the data findings obtained to prove that the increase in the average value of experimental class more higher compared to the control class. On its average value increase control class from 41,36 became 70. While in the average increase in the experimental class from 48,64 became 79,54.. Based on the results of data analysis obtained information that the increase of students' understanding on the text of fairy tales in the classroom that uses the media of the picture story is better than the increase of students in the class that does not use pictorial media. Therefore, it is concluded that the pictorial story media have an influence on reading comprehension students on the narrative text in elementary school.
\end{abstract}

Keywords: Pictorial Story Media, Narrative Texts, Reading Comprehension.

\section{Abstrak}

Penelitian ini dilatar belakangi oleh kurangnya minat dan antusias siswa dalam kegiatan membaca cerita sehingga tidak bisa memahami isi dari cerita tersebut. Untuk mengatasi masalah tersebut, peneliti memilih media konkret cerita bergambar terhadap peningkatan membaca pemahaman siswa pada pembelajaran Bahasa Indonesia. Rumusan masalah dalam penelitian ini secara umum yaitu bagaimana pengaruh media cerita bergambar terhadap membaca pemahaman pada teks dongeng di kelas III SD Negeri Mancogeh Kecamatan Cipedes Kota Tasikmalaya. Tujuan dari penelitian ini secara umum untuk mengetahui pengaruh media cerita bergambar terhadap membaca pemahaman pada teks dongeng, siswa kelas III SD Negeri Mancogeh Kecamatan Cipedes Kota Tasikmalaya. Metode yang digunakan dalam penelitian ini adalah Quasi Eksperimental Design dengan bentuk Nonequivalent Control Group Design. Teknik pengumpulan data dalam penelitian ini yaitu dengan teknik tes, observasi dan dokumentasi. Populasi dalam penelitian ini adalah siswa kelas III SD Negeri Mancogeh, dengan teknik pengambilan sampel berupa sampel jenuh. Adapun instrumen yang digunakan adalah soal tes berupa soal uraian. Analisis data kuantitatif menggunakan Microsoft Excel 2010 dan program SPSS versi 16.0. Setelah penelitian ini dilakukan, diperoleh data kemudian data tersebut diolah dan dianalisis, sehingga temuan yang diperoleh membuktikan bahwa kenaikan nilai rata-rata kelas eksperimen lebih tinggi dibandingkan dengan kelas kontrol. Pada kelas kontrol kenaikan nilai rata-ratanya dari 41,36 menjadi 70. Sedangkan pada kelas eksperimen kenaikan rata-ratanya adalah 48,64 menjadi 79,54. Berdasarkan hasil analisis data tersebut diperoleh informasi bahwa peningkatan pemahaman siswa pada teks dongeng di kelas yang menggunakan media cerita bergambar lebih baik dari pada peningkatan siswa di kelas yang tidak menggunakan media cerita bergambar. Maka dari itu, disimpulkan bahwa media cerita bergambar mempunyai pengaruh terhadap membaca pemahaman siswa pada teks dongeng di Sekolah Dasar.

Kata Kunci: Media Cerita Bergambar, Teks Dongeng, Membaca Pemahaman. 


\section{PENDAHULUAN}

Pada dasarnya bahasa berperan penting dalam kelangsungan berkomunikasi. Melalui bahasa manusia dapat berkomunikasi dengan manusia lainnya. Selain itu, bahasa merupakan penunjang sekaligus pengantar keberhasilan seseorang dalam mempelajari semua bidang ilmu, salah satunya pada mata pelajaran Bahasa Indonesia. Hal ini sejalan dengan penjelasan Cahyani (dalam Aryanto, 2014, hlm. 12) bahwa "bahasa memiliki peran sentral dalam perkembangan intelektual, sosial dan emosional siswa dan merupakan penunjang keberhasilan dalam mempelajari bidang studi”. Penjelasan tersebut menjelaskan bahwa pembelajaran Bahasa Indonesia berperan penting dalam mengembangkan pengetahuan siswa. Dalam pembelajaran bahasa Indonesia, terdapat empat keterampilan berbahasa yang harus dikuasai oleh siswa, yaitu: keterampilan menyimak, keterampilan berbicara, membaca dan menulis.

Sebagaimana yang dikemukakan oleh Tarigan (dalam Nuraeni, 2015 hlm.3), bahwa keterampilan berbahasa mempunyai empat komponen yaitu : a) keterampilan menyimak (listening skill); b) keterampilan berbicara (speaking skill); c) keterampilan membaca (reading skill); d) keterampilan menulis (writing skill). Keterampilan membaca sebagai salah satu cara dari empat keterampilan berbahasa, berperan penting dalam proses mencari ilmu pengetahuan. Menurut Haris dan Sipay (dalam Resmini dan
Hartati, 2006, hlm. 107) "Membaca merupakan proses memperoleh makna dari cetakan".

Keterampilan siswa dalam membaca merupakan salah satu aspek terpenting dalam memahami isi cerita. Agar siswa dapat memahami isi cerita dibutuhkan keseriusan dan keterampilan yang baik, sehingga siswa dapat memahami isi cerita dengan baik.

Salah satu kompetensi yang harus dimiliki siswa berkaitan dengan keterampilan membaca khususnya kelas III yang terdapat dalam Kurikulum Tingkat Satuan Pendidikan (KTSP).

SK KD Membaca Bahasa Indonesia SD Kelas III Semester 2

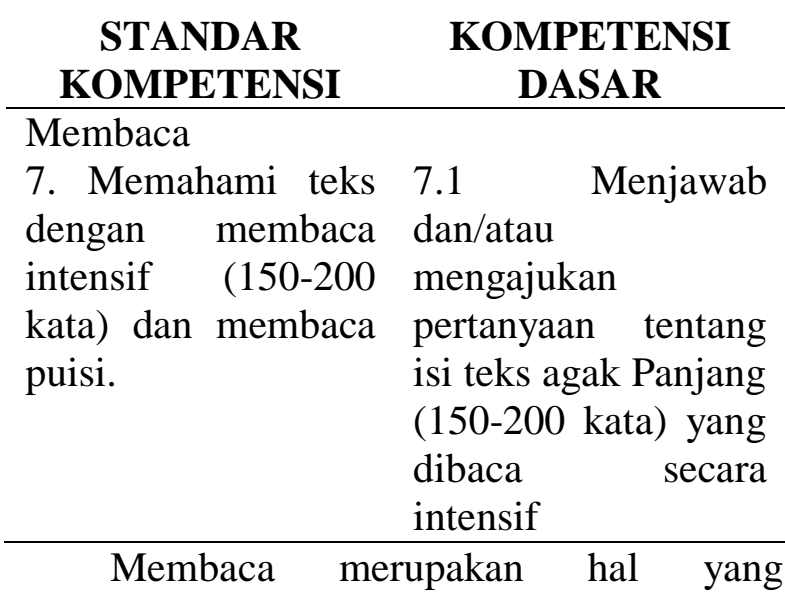
dibutuhkan dari proses Pendidikan. Membaca pemahaman dilakukan untuk memahami isi bacaan yang dibacanya. Sejalan dengan pendapat Juanda (dalam Nuraeni, 2015, hlm. 13) bahwa "membaca pemahaman adalah salah satu bentuk dari kegiatan membaca dengan tujuan utamanya untuk memahami isi pesan yang terdapat dalam bacaan". Agar siswa memahami isi bacaan, maka dibutuhkan keterampilan membaca yang baik. Sehingga 
mempermudah berkomunikasi dengan orang lain.

Dalam proses belajar mengajar di kelas guru sangat berperan penting. Siswa harus tetap mendapatkan bimbingan dan arahan untuk dapat belajar dengan baik terutama dalam keterampilan membaca. Berdasarkan hasil observasi di kelas III SDN Mancogeh mengenai keterampilan siswa dalam membaca pemahaman terutama memahami isi cerita masih kurang. Siswa masih kesulitan dalam memahami isi cerita. Hal tersebut disebabkan media yang digunakan dalam pembelajaran masih berupa teks bacaan biasa, sehingga membuat siswa kurang antusias dalam membaca.

Adapun salah satu cara agar siswa antusias membaca, terutama memahami isi cerita diperlukan media pembelajaran yang dapat membuat siswa tertarik dalam membaca, mempermudah memahami isi bacaan. Media pembelajaran sebagai perantara atau pengantar untuk menyalurkan pesan berupa informasi dalam proses pembelajaran. Menurut Aqib (dalam Nuraeni, 2015, hlm. 3) "media pembelajaran hanyalah dianggap sebagai alat untuk membantu guru dalam kegiatan mengajar". Berdasarkan asumsi tersebut, agar lebih menarik dan menumbuhkan motivasi siswa terhadap isi bacaan, diperlukan media yang dapat menyalurkan imajinasi yang kreatif pada siswa agar dapat memahaminya.
Media pembelajaran yang dapat menjadi alternatif agar siswa dapat memahami isi cerita adalah media cerita bergambar. Cerita bergambar merupakan salah satu kesatuan cerita yang disertai dengan gambar-gambar berfungsi untuk penghias dan pendukung cerita yang dapat membantu memahami isi cerita tersebut. Menurut Mitchel (dalam Nraeni, 2015, hlm. 23) "Cerita bergambar adalah sebuah buku yang didalamnya mengandung kalimat atau kata-kata dan terdapat unsur gambar sebagai pelengkap". Media cerita bergambar dapat mengurangi kejenuhan pada pelajaran keterampilan membaca yang pada akhirnya siswa akan lebih memahami isi cerita yang dibacanya. Dengan media cerita bergambar diharapkan dapat membantu siswa dalam memahami isi cerita.

Oleh karena itu, penelitian ini merupakan alternatif agar siswa lebih terampil dalam memahami isi cerita. Untuk itu peneliti akan melakukan penelitian dengan menggunakan metode Quasi eksperimental. Dengan judul "Pengaruh Media Cerita Bergambar Terhadap Membaca Pemahaman Pada Teks Dongeng Di SD".

\section{METODE PENELITIAN}

Desain penelitian yang digunakan yaitu bentuk Quasi Experimental Design dengan bentuk Nonequivalent Control Group Design. Dalam desain ini siswa akan diberikan tes awal (pretest) sebelum diberi perlakuan, 
ketika sudah diberi perlakuan kemudian siswa diberikan tes Khir (Posttest).

Menurut Sugiyono (2016, hlm. 79) "desain ini memilih dua kelompok; satu kelompok dijadikan sebagai kelompok yang akan memperoleh perlakuan dan satu kelompok lagi dijadikan kelompok kontrol".

Secara jelas bentuk nonequivalent control group design dapat digambarkan sebagai berikut:

\begin{tabular}{|llll|}
\hline $\mathrm{E}$ & $\mathrm{O}_{1}$ & $\mathrm{X}$ & $\mathrm{O}_{2}$ \\
$\mathrm{~K}$ & $\mathrm{O}_{3}$ & & $\mathrm{O}_{4}$ \\
\hline
\end{tabular}

Keterangan:

$\mathrm{E} \quad=$ kelas eksperimen

$\mathrm{K}=$ kelas control

$\mathrm{O}_{1}=$ nilai pretest kelompok eksperimen

$\mathrm{O}_{2}=$ nilai posttest kelompok eksperimen

$\mathrm{O}_{3}=$ nilai pretest kelompok control

$\mathrm{O}_{4}=$ nilai posttest kelompok control

$\mathrm{X}=$ treatment yang diberikan

Populasi yang digunakan dalam penelitian ini adalah siswa kelas SD Negeri Mancogeh Kecamatan Cipedes Kota Tasikmalaya. Adapun sampel yang digunakan adalah siswa kelas III-A SD Negeri Mancogeh yang berjumlah 22 orang sebagai kelompok eksperimen dan siswa kelas III-B SD Negeri Mancogeh yang berjumlah 22 orang sebagai kelompok kontrol.

Teknik pengumpulan data yang digunakan yaitu teknik tes, observasi dan dokumentasi. Adapun instrumen dalam penelitian ini adalah soal tes berupa soal uraian yang pada pelaksanaannya dilakukan sebanyak dua kali, yaitu pretest dan posttest di kelas kontrol dan di kelas eksperimen. Data hasil pretest dan posttest diolah dengan menggunakan data statistik. Statistik yang digunakan adalah statistik deskriptif dan statistik inferensial. Untuk memperudah data diproses peneliti menggunakan bantuan Microsoft Excel 2010 dan program SPSS versi 16.0 for windows.

\section{HASIL DAN PEMBAHASAN}

Penelitian ini dilakukan dengan tujuan untuk mengetahui pengaruh media cerita bergambar terhadap pemahaman siswa pada teks dongeng dengan menggunakan media cerita bergambar dan sejauh mana pemahaman siswa pada teks dongeng dengan menggunakan media cerita bergambar dan tanpa menggunakan media cerita bergambar, juga untuk mengetahui perbedaan peningkatan pemahaman siswa pada teks dongeng antara kelas yang pembelajarannya menggunakan media cerita bergambar dengan kelas yang pembelajarnnya tidak menggunakan media cerita bergambar.

\section{Analisis data kelas kontrol}

Peningkatan pemahaman siswa dilihat dari hasil pretest dan posttest di kelas yang pembelajarannya tidak menggunakan media cerita bergamar. 
Tabel 1

Rekapitulasi Peningkatan Pemahaman Siswa Kelas Kontrol

\begin{tabular}{cccccc}
\hline & Tingkat & \multicolumn{2}{c}{ Frekuensi } & \multicolumn{2}{c}{ Persentase } \\
\cline { 3 - 6 } No. & $\begin{array}{c}\text { Penguas } \\
\text { aan }\end{array}$ & $\begin{array}{c}\text { Pre } \\
\text { test }\end{array}$ & $\begin{array}{c}\text { Pos } \\
\text { ttest }\end{array}$ & Pretest & Posttest \\
\hline 1 & $\begin{array}{c}\text { Sangat } \\
\text { Tinggi }\end{array}$ & 1 & 7 & $4,54 \%$ & $31,82 \%$ \\
\hline 2 & Tinggi & 4 & 13 & $18,18 \%$ & $59,09 \%$ \\
\hline 3 & Sedang & 5 & 0 & $22,73 \%$ & $0 \%$ \\
\hline 4 & Rendah & 7 & 2 & $31,82 \%$ & $9,09 \%$ \\
\hline 5 & $\begin{array}{c}\text { Sangat } \\
\text { Rendah }\end{array}$ & 5 & 0 & $22,73 \%$ & $0 \%$ \\
\hline
\end{tabular}

Berdasarkan tabel di atas, diketahui bahwa hasil pretest terdiri dari 5 kategori yaitu sangat tinggi, tinggi, sedang, rendah dan sangat rendah. Kategori sangat tinggi sebanyak 1 siswa yaitu 4,54\%, kriteria tinggi sebanyak 4 siswa yaitu 18,18\%, kriteria sedang sebanyak 5 siswa yaitu 22,73\%, kriteria rendah sebanyak 7 siswa yaitu $31,82 \%$, dan untuk kriteria sangat rendah sebanyak 5 siswa yaitu $22,73 \%$.

Adapun hasil posttest di kelas kontrol terdiri dari kategori sangat tinggi, tinggi dan rendah. Pada kategori sangat tinggi sebanyak 7 siswa yaitu 31,82\%, kriteria tinggi sebanyak 13 siswa yaitu 59,09\% dan untuk kriteria rendah sebanyak 2 siswa yaitu 9,09\%,. Dapat disimpulkan bahwa pemahaman siswa di kelas kontrol terdapat perubahan pada nilai yang diperoleh siswa. Hal tersebut dapat diketahui dari peningkatan hasil pretest dan posttest siswa di kelas kontrol. Akan tetapi jika dilihat dari nilai rata-rata n-gainnya berada pada kategori kurang efektif sebesar 0,48 .
2. Analisis data kelas eksperimen

Tabel 2

Rekapitulasi Peningkatan Pemahaman Siswa Kelas Eksperimen

\begin{tabular}{cccccc} 
& Tingkat & \multicolumn{2}{c}{ Frekuensi } & \multicolumn{2}{c}{ Persentase } \\
\cline { 3 - 6 } No. Penguasa & an & $\begin{array}{c}\text { Pre } \\
\text { test }\end{array}$ & $\begin{array}{c}\text { Pos } \\
\text { ttest }\end{array}$ & Pretest & Posttest \\
\hline 1 & $\begin{array}{c}\text { Sangat } \\
\text { Tinggi }\end{array}$ & 1 & 14 & $9,09 \%$ & $63,64 \%$ \\
\hline 2 & Tinggi & 8 & 7 & $13,64 \%$ & $31,82 \%$ \\
\hline 3 & Sedang & 4 & 1 & $22,73 \%$ & $4,54 \%$ \\
\hline 4 & Rendah & 7 & 0 & $31,82 \%$ & $0 \%$ \\
\hline 5 & $\begin{array}{c}\text { Sangat } \\
\text { Rendah }\end{array}$ & 2 & 0 & $22,73 \%$ & $0 \%$ \\
\hline
\end{tabular}

Berdasarkan tabel di atas, diketahui bahwa hasil pretest terdiri dari 5 kategori yaitu sangat tinggi, tinggi, sedang, rendah dan sangat rendah. Kategori kriteria interval sangat tinggi sebanyak 1 siswa yaitu 4,54\%, untuk kriteria tinggi sebanyak 8 siswa yaitu $36,36 \%$, kriteria sedang sebanyak 4 siswa yaitu $18,18 \%$, kriteria rendah sebanyak 7 siswa yaitu $31,82 \%$, dan kriteria sangat rendah sebanyak 2 siswa yaitu 9,09\%.

Setelah peneliti melakukan treatmen di kelas eksperimen, dimana dalam proses pembelajarannya menggunakan media cerita bergambar sebagai media konkrit untuk pembelajaran siswa pada teks dngeng, didapat hasil posttest siswa yang terdiri dari kategori sangat tinggi, tinggi dan sedang. Pada kategori sangat tinggi sebanyak 14 siswa yaitu 63,64\%, kriteria tinggi sebanyak 7 siswa yaitu $31,82 \%$ dan sedang seanyak 1 siswa yaitu $4,54 \%$.

Dapat disimpulkan bahwa pemahaman siswa di kelas eksperimen terdapat perubahan 
pada nilai yang diperoleh siswa. Hal tersebut dapat diketahui dari peningkatan hasil pretest dan posttest siswa di kelas eksperimen. Dilihat dari nilai rata-rata n-gainnya berada pada kategori cukup efektif sebesar 0,64.

\section{Analisis Peredaan Peningkatan Pemahaman Siswa Kelas Kontrol dan Kelas Eksperimen}

Tabel 3

Hasil Rekapitulasi n-gain Kelas Kontrol dan Kelas Eksperimen

\begin{tabular}{|c|c|c|c|}
\hline No. & $\begin{array}{l}\text { Kode } \\
\text { Siswa }\end{array}$ & $\begin{array}{c}\text { n-gain Kelas } \\
\text { Kontrol }\end{array}$ & $\begin{array}{c}\text { n-gain Kelas } \\
\text { Eksperimen }\end{array}$ \\
\hline 1 & S-1 & 0,57 & 0,44 \\
\hline 2 & S-2 & 0,20 & 0,5 \\
\hline 3 & S-3 & $-0,20$ & 0,75 \\
\hline 4 & S-4 & 0,57 & 0,57 \\
\hline 5 & S-5 & 0,57 & 0,2 \\
\hline 6 & S-6 & 0,50 & 0,75 \\
\hline 7 & S-7 & 0,50 & 0,5 \\
\hline 8 & S-8 & 1,00 & 0,67 \\
\hline 9 & S-9 & 0,50 & 0,75 \\
\hline 10 & S-10 & 0,50 & 0,62 \\
\hline 11 & S-11 & 0,87 & 0,4 \\
\hline 12 & S-12 & 0,40 & 0,5 \\
\hline 13 & S-13 & 0,60 & 0,6 \\
\hline 14 & S-14 & 0,25 & 0,43 \\
\hline 15 & S-15 & 0,25 & 0,6 \\
\hline 16 & S-16 & 0,67 & 1 \\
\hline 17 & S-17 & 0,57 & 0,75 \\
\hline 18 & S-18 & 0,25 & 1 \\
\hline 19 & S-19 & 0,83 & 0,67 \\
\hline 20 & S-20 & 0,87 & 1 \\
\hline 21 & S-21 & 0,20 & 0,71 \\
\hline 22 & S-22 & 0,83 & 0,71 \\
\hline \multicolumn{2}{|c|}{ Jumlah } & 10,48 & 14,13 \\
\hline \multicolumn{2}{|c|}{ Mean } & 0,48 & 0,64 \\
\hline \multicolumn{2}{|c|}{ Median } & 0,50 & 0,65 \\
\hline \multicolumn{2}{|c|}{ Minimum } & $-0,20$ & 0,20 \\
\hline \multicolumn{2}{|c|}{ Maximum } & 1,00 & 1,00 \\
\hline
\end{tabular}

Dari tabel di atas, diketahui bahwa nilai rata-rata $n$-gain kelas kontrol adalah 0,48 dan rata-rata $n$-gain kelas eksperimen adalah 0,64.
Hal ini menunjukkan kualitas peningkatan pemahaman siswa kelas eksperimen lebih tinggi dibanding kelas kontrol. Jadi dapat disimpulkan bahwa pemahaman siswa pada teks dongeng di kelas eksperimen yang proses pembelajarannya menggunakan media cerita bergambar lebih baik dengan siswa di kelas kontrol yang tidak menggunakan media cerita bergambar.

Pembahasan hasil penelitian dimaksudkan untuk mengetahui lebih jelas mengenai pengaruh media cerita bergambar terhadap pemahaman pada teks dongeng. Pada pembahasan ini dipaparkan bagaimana pemahaman siswa tanpa mengguanakan media cerita bergambar, pemahaman siswa dengan menggunakan media cerita bergambar, perbedaan peningkatan pemahaman kelas kontrol dan kelas eksperimen, serta pengaruh media cerita bergambar terhadap pemahaman siswa pada teks dongeng di kelas eksperimen.

Peneliti melakukan persiapan sebelum melaksanakan penelitian, yaitu membuat intrumen penelitian berupa soal uraian tentang dongeng fabel berjumlah 10 soal. Kemudian peneliti melakukan uji validitas soal, uji reliabilitas, uji daya pembeda dan uji tingkat kesukaran soal. Dari jumlah 10 soal, seluruh soal valid dan reliabel. Kemudian 10 soal yang peneliti gunakan untuk dijadikan tolak ukur dalam penelitian yang akan dilakukan. Selain itu, karena dalam penelitian ini hal yang dijadikan fokus adalah mengetahui 
pengaruh media konkret terhadap pemahaman siswa pada teks dongeng, maka peneliti menggunkan media cerita bergambar dalam pembelajarannya.

Langkah selanjutnya setelah melakukan persiapan yaitu peneliti mengambil data penelitian berupa pemberian pretest kepada siswa di kelas kontrol dan kelas eksperimen. Dari hasil pretest diketahui nilai rata-rata siswa di kelas kontrol 41,36 dan di kelas eksperimen 48,64. Dari rata-rata hasil pretest kedua kelas tersebut, diketahui bahwa nilai rata-rata siswa kelas kontrol berada pada kategori rendah dan rata-rata siswa kelas eksperimen berada pada kategori sedang.

Berdasarkan analisis data pemahaman siswa pada teks dongeng di kelas kontrol dan di kelas eksperimen mengalami peningkatan. Tetapi terdapat perbedaan peningkatan antara kelas kontrol dan kelas eksperimen. Nilai rata-rata $n$-gain kelas kontrol adalah 0,48 dan rata-rata $n$-gain kelas eksperimen adalah 0,64, rata-rata $n$-gain di kelas kontrol berada pada kategori kurang efektif dan rata-rata nilai $n$ gain kelas kontrol berada pada kategori cukup efektif. Kualitas peningkatan pemahaman siswa kelas eksperimen lebih tinggi dibanding kelas kontrol. Jadi dapat diketahui bahwa pemahaman siswa pada teks dongeng di kelas eksperimen yang proses pembelajarannya menggunakan media cerita bergambar lebih baik dibandingkan siswa di kelas kontrol yang tidak menggunakan media cerita bergambar.
Berdasarkan analisis data yang telah dilakukan mulai dari analisis data pemahaman siswa di kelas kontrol, analisis data pemahaman siswa di kelas ekperimen, analisis data perbedaan peningkatan pemahaman siswa di kelas kontrol dan kelas eksperimen, juga analisis data pengaruh media cerita bergambar pada teks dongeng didapatkan hasil pemahaman siswa pada teks dongeng di kelas eksperimen yang proses pembelajarannya menggunakan media cerita bergambar lebih baik dibandingkan siswa di kelas kontrol yang tidak menggunakan media cerita bergambar. Jadi dapat disimpulkan bahwa media cerita bergambar berpengaruh terhadap membaca pemahaman siswa pada teks dongeng di SD Negeri Mancogeh Kecamatan Cipedes Kota Tasikmalaya.

\section{SIMPULAN}

Pemahaman siswa kelas III B SD Negeri Mancogeh Kecamatan Cipedes Kota Tasikmalaya pada teks dongeng berada pada kategori rendah dan tinggi berdasarkan nilai rata-rata pretest dan posttest yang diperoleh siswa. Hal tersebut membuktikan peningkatan pemahaman siswa pada teks dongeng, selain itu peningkatan pemahaman siswa kelas III B pada teks dongeng dapat dilihat dari hasil uji beda rata-rata yang dilakukan dengan membandingkan nilai pretest dan posttes siswa kelas III B SD Negeri Mancogeh. Sedangkan pemahaman siswa kelas III A SD Negeri Mancogeh pada teks dongeng berada pada kategori sedang dan sanga tinggi. Hal 
tersebut membuktikan peningkatan pemahaman siswa pada teks dongeng, selain itu peningkatan pemahaman siswa kelas III B pada teks dongeng dapat dilihat dari hasil uji beda rata-rata yang dilakukan dengan membandingkan nilai pretest dan posttes siswa kelas III B SD Negeri Mancogeh.

Terdapat perbedaan peningkatan pemahaman siswa pada teks dongeng SD Negeri Mancogeh Kecamatan Cipedes Kota Tasikmalaya yang pembelajarannya menggunakan media cerita bergambar dan yang pembelajarannya tidak menggunakan media cerita bergambar. Dimana pemahaman siswa pada teks dongeng di kelas yang proses pembelajarannya menggunakan media cerita bergambar lebih baik dibandingkan kelas yang tidak menggunakan media cerita bergambar, hal tersebut berdasar uji perbedaan rata-rata nilai $\mathrm{n}$-gain di kedua kelas.

Pengaruh media cerita bergambar yaitu dapat meningkatkan pemahaman siswa pada teks dongeng di kelas III SD Negeri Mancogeh Kecamatan Cipedes Kota Tasikmalaya, dibuktikan dengan hasil adanya perbedaan peningkatan pemahaman yang lebih baik antara kelas yang menggunakan media cerita bergambar dan kelas yang tidak menggunakan media cerita bergambar.

\section{DAFTAR PUSTAKA}

Aryanto, A. (2013). Media Pembelajaran. Jakarta: PT Grafindopersada

Nuraeni, I. (2015). Pengaruh Media Cerita Bergambar Terhadap Keterampilan
SIswa dalam Membaca Pemahaman. UPI Kampus Tasikmalaya

Resmini, dkk.(2006).Membaca dan Menulis di SD.Teori dan Pengajarannya.Bandung : UPI PRESS.

Sugiyono. (2016). Metode penelitian pendidikan (pendekatan kuantitatif, kualitatif dan $r \& d$. Bandung. Alfabeta. 